\title{
Ageism in ICU: Knowledge, Attitude and Advocacy toward Caring of Critically ill Elderly Patient
}

\author{
Eman Mohamed Ebrahim ${ }^{1}$, Ghada Abd Elsalam Eldeeb ${ }^{2}$ \& Zahra Ahmed Sayed ${ }^{3 .}$ \\ 1. Lecturer of Geriatric Nursing Department, Faculty of Nursing, Aswan University, Egypt. \\ Currently Faculty of Nursing, Jazan University, KSA. \\ 2. Assistant Professor, Nursing Administration Department, Menoufyia University, Egypt. \\ Currently Faculty of Nursing, Jazan University, KSA. \\ 3. Lecturer of Critical Care Nursing Department, Faculty of Nursing, Aswan University, Egypt
}

\begin{abstract}
:
Elderly patients comprise an increasing of intensive care unit (ICU) admissions. So, the great importance to focus on attitudes of critical care nurses, those who give a direct care to the elderly patients and their positive attitudes towards elders and adequate knowledge care would improve the quality of care. Aim: to assess ageism in ICU, critical care nurse's knowledge, attitude and advocacy toward caring for critically ill elderly patients. Methods: A descriptive cross-sectional design. Setting 9 ICU at Aswan city hospital. Subjects: A purposive sample 114 nurses. Tools were used to collect data; socio-demographic data of critical care nurses, the Ageism Attitude Scale (AAS), protective nursing advocacy scale and a self-administered knowledge questionnaire. Results: Highest percentage of study subjects had low levels of attitude regarding positive ageism domain and total ageism score (93\%) and (59.6\%) respectively. (79.8\%) have good knowledge, and a majority of study subjects had a moderate level of advocacy. Conclusion: the non-significantly relationship between nurses' knowledge, attitudes toward ageism and geriatric patient advocacy behaviors. Recommendations: continuing education for a critical care nurses caring for elderly, especially in ICU in order to enforce positive attitudes towards elderly and improve behaviors by increasing their knowledge
\end{abstract}

\section{Keywords: ICU, Ageism, Attitudes, Advocacy, Critical Care Nurses, Critically Ill, knowledge \& Elderly Patients.}

\section{Introduction}

The percentage of the elderly population is continuously increasing globally due to the decline in overall death rate, decline and fertility, with sustained improvement in survival. Specific to the region of Africa and the Middle East, Egypt is expected to maintain the highest rank in absolute numbers of old and oldest-old populations in the region by the year 2050 (Sweed, 2016) .

Aging seldom arises alone, often being associated with chronic illnesses, comorbidity, disability, frailty, functional insufficiencies, and social isolation. Multiple diseases predictably lead to the use of multiple drugs, a condition known as polypharmacy which requires readmission of the older adult clients to the hospitals especially in the critical care setting. At least, more than semi- of the patients admitted to the intensive care unit are older than 65 years (Caterino et al., 2019) Mortality and morbidity in elderly patients charged to the ICU are higher than in younger patients. The more important risk factors independently associated with the highest risk of death are the acuity of illness, compromised level of consciousness, and infection (Liang et al., 2019)
Nurses have expressed negative bias against older adults and preference for working with younger people because of concerns about a professional disregard from selecting to work with elderly people and because of the low status of older people care in the health care setting, this leads to inadequate allocation of health services and elder mistreatment (Abdou \& Baumbusch., 2016)

Identifying biases constitutes the first step in addressing nurses' ageism toward older adults discrimination can be caused by their culturally inherited beliefs and experiences about old age which called ageism (Oral, et al., 2019)

Ageism is discernment against geriatric people include stereotyping and negative attitudes toward people because of their age stage, as viewing all elderly people are dependent, fragile persons, cannot or should not participate in societal activities, and should not be given equal opportunities afforded to others (Mohammed et al., 2019).

Ageism in critical care settings lead to a lack in communication and to facilitate understanding in the elderly reduces their awareness and, screening. It also reduces some preventive health services shortages of prescriptions and treatment for the elderly (Berger et al., 2017) 
The lack of interest on the part of many nurses to go into gerontological nursing makes older adults even more vulnerable to functional disabilities and diminished quality of life (Butting et al., 2018).

However, lack of knowledge, pervasive negative attitudes and ageism in nursing toward older adults hinder this urgent need and reflected in delay or omission of a required health care intervention for geriatric especially patients in ICU or may not receive the same efficiency of health care services compared to younger patients (de Almeida et al., 2015) \& (Ben-Harush., 2017).

Therefore, nurses must have sufficient knowledge and skills demonstrate appropriate attitudes toward older people, and prepared well to meet the challenges of caring for this rapidly increasing the segment of the population including their advocacy roles for older adults (Tomaschewski et al., 2016).Advocacy behaviors as an established part of the extremely important roles of the nurse's role may be influenced by the nurses' ageist attitude (Barlem et al., 2018). This expectation can be traced back to Ajzen's Theory of Planned Behavior (TPB), which highlighted that individuals' attitudes are imperative signs of their behavioral objectives (Nelson et al., 2014).

The role of nurses in advocacy has been defined as the voice of patients, to help the patients to obtain the necessary health care, defend their rights, ensure the quality of care and serve as a link between the patient and the healthcare environment (Smith, 2015). Moreover, geriatric patients' protection against harm cannot be maintained. In addition to the current, impaired of nurses' advocacy manners leaving geriatric patients within the ICU at a greater risk for increased rate of iatrogenic complications like falls, loss of mobility delirium, incontinence, and nosocomial infections as well as an increased threat of mortality and length of stay (Caceres, 2019).

critical care nurses need an adequate level of knowledge and attitudes of the aging affect their prospects about their methods of care for elderly individuals also satisfactory knowledge and clinical practice on senility mitigates negative attitudes against the older persons and prompts the expansion of positive attitudes regarding care for older persons (Abudu-Birresborn et al ., 2019).

\section{Significance of the study}

Elderly patients comprise a growing ratio of intensive care unit (ICU) charges. Advanced age and several comorbidities compromise their immunity and hence they may be more prone to succumbing to severe infection and have worse outcomes (schulte et al., 2016). There are several related work of the literatures demonstrated that there is a lack of educational training programs focusing on gerontological nursing for all categories of nurses who work with older persons and the given healthcare services for older adults has been severely showing by the negative stereotypic approaches and misconceptions of nurses, with $63 \%$ of older adult expressing an unmet health need (Doherty et al., 2016).

A recent study showed that nurses $(75 \%)$ and medical doctors (54\%) think that elderly patients receive lowe -quality healthcare than younger patients. This apparent inconsistency hints to health professionals distinguish against aged patients and believe elderly patients have gotten their share of government financed management during their age stage already, thus younger patients should be prioritized (Bartt et al., 2016).

Hence this study was carried out to analyze the critical care nurse's knowledge, attitude and, advocacy toward critically ill elderly patient within ICU.

Aim of the study was to assess ageism in ICU, critical care nurse's knowledge, attitude and advocacy toward caring of critically ill elderly patient

\section{Research question}

- What is the critical care nurses' attitudes toward ageism?

- What is the critical care nurses' advocacy toward ageism?

- Is there a relation between critical care nurses' ageism, advocacy attitude and its knowledge toward elderly patients?

\section{Materials \& Method \\ Materials}

Study Design: A descriptive cross-sectional design was used in this study.

Setting: The present study was conducted in 9 intensive care units (ICUs) at Aswan city, hospital, Egypt, Hospital namely (Aswan university hospital, Hospital health insurance, Al-sadka hospital and oncology hospital) intensive care units namely; ( chest ,medical, neurological, anesthesia, postoperative, burn, coronary, oncology, and general intensive care units) .

Subjects: A convenient sample of critical care nurses from the previously mentioned ICUs their total number was 114 nurses

Data collection tools: Four tools were used to collect data of this study

Tool I: Socio-demographic and interview of critical care nurses' questionnaire sheet

This tool was developed by the researchers based on review of relevant literature to collect information about related to critical care nurses' characteristics such as age, gender, marital status, residence, the type 
of unit is currently working in, educational qualification and years of experience as well as receiving of any formal training in caring for older adults.

Tool II: The ageism attitude scale (AAS) It was adopted by (Vefikulucay \& Terzioglu 2011) developed and modified by the current researchers. It was used to evaluate critical care nurses attitudes to ageism through 23 items clustered under three dimensions: restricting life of older adult (9 items), positive ageism ( 8 items), and negative ageism (6 items). The responses are estimated by a 5-point Likert scale ranged from strongly agree to strongly disagree. The items including negative attitude phrases were reversely coded. The highest score for the scale was " 115 " and the lowest was " 23 ." Upper total scale scores display positive attitudes to ageism and lower scores determines negative attitudes of participants.

Tool III: The quantitative Protective Nursing Advocacy Scale (PNAS)

It was developed by (Hanks 2010) to measure advocacy from the perspective of protecting patients in an acute care environment. It was slightly modified by the current researchers by adding the ward geriatric before the ward patient to specify perception of advocacy behaviors toward geriatric patient. The PNAS tool was used to measure advocacy from the beliefs and actions of critical care nurses protecting their patients in the ICU. The PNAS questionnaire contained four nurse advocacy components: acting as advocate (16 items), work status and advocacy actions (5 items), environment and educational influences (8 items), and support and barriers to advocacy (4 items), and methodological domain contains 5 items. The tool consisted of 38 -items measured on a five point Likert scale ranging from 5 (strongly agree) to 1 (strongly disagree) for each question. The possible scores of PNAS are categorized using the following percentiles:

- Score 0 to 95 indicates low perceived advocacy.

- Score 95 to less than 142 indicates moderate perceived advocacy.

- Score 142 and more indicates high perceived advocacy.

Tool IV: Self-administered knowledge questionnaire care of critically ill older patients:

Questionnaire used by (Kaur,et al 2014) was used in this study, it was consisted of 28 dichotomous questions with one right answer related to care of elderly people. Has been used to identify critical care nurse knowledge about elderly care. Total Knowledge score was categorized as poor, average and good as per the score obtained by the subjects i.e. $>15,15-20$, and 21-27 respectively.

\section{Method}

- Official letters were delivered from the Faculty of Nursing, to the administrator's manger of the study settings to obtain their permission to carry out the study after explaining the purpose of the study. Then, a written approval to carry out the study was obtained from the hospital responsible authorities at the previous mentioned settings. Lastly, the heads of the nine intensive care units were informed about the purpose of the study, the date and the time of starting data collection.

- Tool II (The ageism attitude scale), tool III Protective Nursing Advocacy Scale (PNAS) and Tool IV (Self-administered knowledge questionnaire care of care older patients) were translated into Arabic by the researchers and tested for content validity by submitting the Arabic and English copy to five experts in the field of the study. No modifications are suggested.

- Reliability test of tool II, III and Tool IV was done using Cronbach's alpha statistical test to measure the internal consistency of the three scales items. Alpha Cronbach's reliability coefficient of tools was (0.817 for tool II, and 0. 896 for tool III).

- An intended questionnaire survey was conducted on subject and informed about the aim of the study and assured about the confidentiality of his/ her response. Each subject was contact on an individual basis, and was interviewed in a private place by the researchers used the three study tools. The average time needed to complete the tools ranged between 15 to 20 minutes. Data for this study was collected during a period of 4 months, from the beginning of April until the end of August 2020.

- A pilot study was carried out on 12 nurses to assess the applicability, clarity and feasibility of the study tools, and to determine also, the estimated time to complete the study tools. Those nurses were not included in the study subjects. Based on pilot study findings' the needed modifications were done.

\section{Statistical analysis}

After data were collected, they were coded and transferred into especially design formats to be suitable computer feeding. The statistical package of social science (SPSS) version 25. 0 was utilized for data analysis and tabulation all entered data were verified for errors. A $p$-value of 0.1 and 0.05 levels were used as the cut off value for statistical significance. Correlation, mean, and standard deviation were used to test the significance of some related variables in this study. 


\section{Ethical considerations}

Official permission from the hospitals and nursing directors and authorized personnel in ICU unit to data collection. Participation in this study was fully voluntary and were informed that they can leave at any time during the study without giving reasons, the data collected will be used only for research purpose, and data collection was totally anonymous as no personal identification information was obtained.

\section{Results}

Table (1): Sociodemographic characteristics of study nurses at Aswan City, 2020.

\begin{tabular}{|l|c|c|}
\hline \multicolumn{1}{|c|}{ Characteristic } & No & \% \\
\hline Age & & \\
$<30$ & 54 & 47.4 \\
$30-40$ & 56 & 49.1 \\
$>40$ & 4 & 3.5 \\
\hline Experience & 16 & 14 \\
<1 year & 72 & 63.2 \\
1 - 5 years & 20 & 17.5 \\
$5-10$ years & 4 & 3.5 \\
10-15 years & 2 & 1.75 \\
$>$ 15 years & & \\
\hline Gender & 40 & 35.1 \\
Male & 74 & 64.9 \\
Female & & \\
\hline Marital status & 86 & 75.4 \\
Single & 26 & 22.8 \\
Married & 2 & 1.75 \\
Divorced & & \\
\hline Type of community & 56 & 49.1 \\
Urban & 58 & 50.9 \\
Rural & & \\
\hline Unit & 20 & 17.5 \\
Burn ICU & 18 & 15.8 \\
Chest ICU & 4 & 3.5 \\
Neurological ICU & 4 & 3.5 \\
Anesthesia ICU & 8 & 7 \\
Post-operative ICU & 18 & 15.8 \\
General ICU & 18 & 15.8 \\
Coronary care unit (CCU) & 18 & 15.8 \\
Medical ICU & 6 & 5.3 \\
Oncology ICU & 56 & 3.5 \\
\hline Qualifications & 58 & 12.3 \\
Diploma School in nursing & & \\
Nurse Institute diploma & & 59.1 \\
Bachelor degree & & 50.9 \\
\hline Care of elderly training & & \\
Yes & & \\
No & & \\
\hline & & \\
\hline
\end{tabular}


Table (2): Percentage distribution of ageism Attitude levels among critical care nurse.

\begin{tabular}{|l|c|c|c|c|c|c|}
\hline \multirow{2}{*}{\multicolumn{1}{c|}{ Ageism DOMAINS }} & \multicolumn{2}{c|}{ high } & \multicolumn{2}{c|}{ Neutral } & \multicolumn{2}{c|}{ low } \\
\cline { 2 - 8 } & No & \% & No & \% & No & \% \\
\hline Restricting life of elderly & 58 & 50.9 & 54 & 47.4 & 2 & 1.8 \\
\hline Positive ageism & 0 & 0 & 8 & 7.0 & 106 & 93.0 \\
\hline Negative ageism & 36 & 31.6 & 70 & 61.4 & 8 & 7 \\
\hline Total ageism attitude & 0 & 0 & 46 & 40.4 & 68 & 59.6 \\
\hline
\end{tabular}

Table (3): Mean scores of study subjects` ageism attitude domains.

\begin{tabular}{|l|c|c|c|c|}
\hline \multicolumn{1}{|c|}{ Ageism Domains } & Mean & 土SD & t & P \\
\hline Restricting life of elderly & 22.56 & 3.46 & $69.54^{*}$ & 0.01 \\
\hline Positive ageism & 12.16 & 2.74 & $47.41^{*}$ & 0.01 \\
\hline Negative ageism & 20.81 & 2.95 & $75.22^{*}$ & 0.01 \\
\hline Total ageism attitude & 55.53 & 4.30 & $137.77^{*}$ & 0.01 \\
\hline
\end{tabular}

*significant at the $<0.05$ level

Table (4): percentage distribution of study subject's total knowledge scores.

\begin{tabular}{|l|c|c|}
\hline \multicolumn{1}{|c|}{ Knowledge } & No & \% \\
\hline Good (21-27) & 91 & 79.8 \\
Average $(15-20)$ & 21 & 18.4 \\
Poor (<15) & 2 & 1.8 \\
\hline Mean \pm SD & \multicolumn{2}{|c|}{$24.16 \pm 3.34$} \\
\hline
\end{tabular}

Table (5): Percentage distribution of study subjects` levels of advocacy.

\begin{tabular}{|l|c|c|c|c|c|c|}
\hline \multirow{2}{*}{\multicolumn{1}{c|}{ Advocacy Domains }} & \multicolumn{2}{c|}{ Low } & \multicolumn{2}{c|}{ Moderate } & \multicolumn{2}{c|}{ High } \\
\cline { 2 - 7 } & No & $\%$ & No & $\%$ & No & $\%$ \\
\hline Acting as advocate & 4 & 3.5 & 70 & 61.4 & 40 & 35.1 \\
\hline Work status and advocacy actions & 16 & 14 & 50 & 43.9 & 48 & 42.1 \\
\hline Environment and education influence & 4 & 3.5 & 40 & 35.1 & 70 & 61.4 \\
\hline Support and barriers & 4 & 3.5 & 52 & 45.6 & 48 & 48.1 \\
\hline Methodological items & 4 & 3.5 & 54 & 47.4 & 56 & 49.1 \\
\hline Total advocacy score & 4 & 3.5 & 68 & 59.6 & 42 & 36.8 \\
\hline
\end{tabular}

Table (6): Mean score of advocacy domains among study subjects.

\begin{tabular}{|l|c|c|c|c|}
\hline \multicolumn{1}{|c|}{ Advocacy Domains } & Mean & +SD & t & P \\
\hline Acting as advocate & 57.39 & 7.04 & 86.98 & 0.01 \\
\hline Work status and advocacy actions & 16.91 & 3.43 & 52.57 & 0.01 \\
\hline Environment and education influence & 29.39 & 3.71 & 84.47 & 0.01 \\
\hline Support and barriers & 14.23 & 1.63 & 93.22 & 0.01 \\
\hline Methodological items & 18.35 & 2.66 & 73.73 & 0.01 \\
\hline TOTAL advocacy score & 136.26 & 14.58 & 99.79 & 0.01 \\
\hline
\end{tabular}

Statistically significant at $p \leq 0.05$ 
Table (7): Correlations between domains of ageism attitude and advocacy.

\begin{tabular}{|l|c|c|c|c|c|c|c|c|}
\hline \multirow{2}{*}{} & \multicolumn{2}{|c|}{$\begin{array}{c}\text { Restricting life of } \\
\text { elderly }\end{array}$} & \multicolumn{2}{c|}{ Positive ageism } & \multicolumn{2}{c|}{ Negative ageism } & \multicolumn{2}{c|}{$\begin{array}{c}\text { Total ageism } \\
\text { score }\end{array}$} \\
\cline { 2 - 10 } & $\mathbf{r}$ & $\mathbf{p}$ & $\mathbf{r}$ & $\mathbf{p}$ & $\mathbf{r}$ & $\mathbf{P}$ & $\mathbf{r}$ & $\mathbf{p}$ \\
\hline Acting as advocate & $.217^{*}$ & .021 & .023 & .812 & $-.210^{*}$ & .025 & .045 & .637 \\
\hline $\begin{array}{l}\text { Work status and } \\
\text { advocacy actions }\end{array}$ & -.067 & .477 & -.047 & .616 & -.085 & .366 & -.143 & .129 \\
\hline $\begin{array}{l}\text { Environment and } \\
\text { education influence }\end{array}$ & $.244^{*}$ & .009 & .024 & .804 & -.180 & .055 & .088 & .352 \\
\hline Support and barriers & .015 & .876 & -.072 & .449 & -.039 & .684 & -.060 & .525 \\
\hline Methodological items & .096 & .311 & -.044 & .641 & $-.235^{*}$ & .012 & -.112 & .234 \\
\hline total advocacy score & .170 & .070 & -.010 & .913 & $-.215^{*}$ & .022 & -.017 & .858 \\
\hline
\end{tabular}

Table (8): Correlation between ageism, knowledge and advocacy.

\begin{tabular}{|c|c|c|c|c|c|c|}
\hline \multirow[t]{2}{*}{ Items } & \multicolumn{2}{|c|}{ Total ageism score } & \multicolumn{2}{|c|}{$\begin{array}{c}\text { Total knowledge } \\
\text { score }\end{array}$} & \multicolumn{2}{|c|}{ Total advocacy score } \\
\hline & $\mathrm{R}$ & $\mathrm{r}$ & $\mathrm{R}$ & $\mathrm{P}$ & $\mathrm{R}$ & $\mathrm{P}$ \\
\hline Total ageism score & \multicolumn{2}{|c|}{1} & .170 & .07 & -.017 & .858 \\
\hline Total knowledge score & .170 & .07 & \multicolumn{2}{|c|}{1} & -.157 & .096 \\
\hline Total advocacy score & -.017 & .858 & -.157 & .096 & \multicolumn{2}{|c|}{1} \\
\hline
\end{tabular}

Statistically significant at $p \leq 0.05$

Table (1): Presents socio demographic characteristics of study subjects. Concerning age less than half of study subjects $(49.1 \%)$ were in the age group $30-40$ years. Nearly two third $(63.2 \%)$ had from 1 to 5 years of experience. regarding gender the highest percentage $(64.9 \%)$ were females. Concerning marital status majority $(75.4 \%)$ of study subjects were single .more than half $(50.9 \%)$ were live in rural community. regarding critical care units, there were highest percentage (17.5\%)from burn ICU, equal percentages (15.8)of nurses from chest ICU, general ICU,CCU, and medical ICU. Also, there were equal percentages of nurses $(3.5 \%)$ from neurological ICU and anesthesia ICU. Concerning qualifications $84.2 \%$ were nurse institute diploma. Round subjects (50.9\%) did not receive training about care of elderly as shown in table (1).

Table (2): Shows distribution of ageism attitude levels among critical care nurses. According to the table more than half of study subjects $(50.9 \%)$ had high level of attitude regarding restricting life of elderly domain. However the highest percentage of study subjects had low levels of attitude regarding positive ageism domain and total ageism score (93\%) and $(59.6 \%)$ respectively. Moreover majority of study subjects (61.4) had neutral attitude towards negative ageism domain.

Table (3): Displays mean scores of study subjects' ageism attitude domains. There were statistical significant differences among study subjects regarding the mean scores of ageism attitude and it's all domains. As well as mean scores for the subscales of the AAS (restricting life of elderly, positive ageism, and negative ageism) were (22.56 \pm 3.46 , $12.16 \pm 2.74$ and $20.81 \pm 2.95)$ respectively showing negative attitudes for each dimension.

Table (4): Shows percentage distribution of study subject's total knowledge scores. According to the table the highest percentage $(79.8 \%)$ of study subjects have good knowledge. the mean \pm SD knowledge were $24.16 \pm 3.34$.

Table (5): Presents percentage distribution of study subjects` levels of advocacy. Majority of study subjects had moderate level of advocacy in total advocacy scores and all domains except environment and education influence domain highest percentage of study subjects (61.4\%) had high level of advocacy.

Table (6): Displays mean scores of study subjects` advocacy domains. There were statistical significant differences among study subjects regarding the mean scores of advocacy and its all domains.

Table (7): Table 6 shows correlations between domains of ageism attitude and advocacy. According to the table there were statistical significant positive correlations between restricting life of elderly and acting as advocate and environment and education influence domains. However there were statistical significant negative correlation between the negative attitude domain and acting as advocate, methodological items and total advocacy score.

Table (8): Presents correlation between ageism, knowledge and advocacy. According to the table there were non-significant statistical negative correlation between ageism and advocacy $(r=-.017, p$ 
$=.858)$; Also between knowledge $(\mathrm{r}=-.157, \mathrm{p}=$ .096) and advocacy. However non-significant statistical positive correlation was found between knowledge and ageism $(r=.170, \mathrm{p}=.07)$.

\section{Discussion}

The elderly are an ever increasing population in overcrowded emergency rooms in many countries. They have multiple health problems and consume more time and resources than younger patients (Rosen et al., 2018). Nursing ageism attitudes and advocacy behaviors can results in lack of provided medical and nursing care, decreased access to services, as well as altered dignity and respect for older adults (Swift et al ., 2017).

So, of great important to investigate nurses' knowledge and focus on attitudes of nursing staff to wards elderly patients who provide the maximum and direct care for elderly patients in the critical care units. Since, attitudes may impact the nurses' performance of care procedures for those grow ing and vulnerable elderly patients.

Results of this study showed that age of the participants was range between $30-40$ years. A round two third of the studied sample ( $64.9 \%$ ) were females also more than half residing in rural areas and did not receive training about care of elderly.

As regarding to critical care nurses ageism attitude toward elderly patient, the majority of the studied sample with negative attitude toward the elderly people and with statistical significant differences among study subjects regarding the mean scores of ageism attitude and it's all domains.

The nurses' negative attitudes toward ageism might be explained by some of possible reasons especially this fact did not reflect our culture especially in Upper Egypt, that respect the elderly and take their point of view seriously; but this finding may be related to hard living conditions, and changing family structure cause value lost towards the elderly and considering care for them as a burden on the family. (Beck et al., 2017), (Kang et al., 2017) \& (Schroyen et al., 2016). Who found the nurses might hold negative attitudes toward older adults for many reasons, including age-related physiological changes, high comorbid burden, and limited healthcare resources.

On the other hand this finding was against results of previous studies conducted by (Özdemir \& Bilgili 2016). Who use the ageism attitude scale and declared that nurses held a generally positive attitude toward aging. Also it was unlike in the same line, other findings from different researches confirmed that not all nurses have a negative attitude towards their older patients (Rhew, 2017, Gillis et al., 2008). The study was examined of critical care nurses regarding to nursing care for acuity elderly patients, nurses in this study had significantly levels of knowledge about aging was consistent with Western and Eastern studies that found nurse have satisfactory level of knowledge related to caring of geriatric patients (Deasey et al., 2018), (Lan et al., 2019). Several factors could explain this finding. Nursing education in the West is characterized by a satisfactory focus on gerontology (Dobrowolska et al., 2019). However, nursing education in Egyptian universities addresses gerontological nursing care in the curriculum to meet healthcare needs and challenge facing nurses with older adult's patients in critical care setting.

Regarding to nursing advocacy the current study showed that majority of study subjects had moderate level of advocacy in total advocacy scores and all domains except environment and education influence had high level of advocacy among study subject. These findings consistent with (Windle et al., 2008) study indicated that nurses have the chance to adjust and influence the way of healthcare providing by their powerful role as advocates of a safe work environment. However ( Josse-Eklund, et al., 2014), justified that the decline of patient advocacy behaviors from the side of nurses may be due to nurses' fear of facing conflicts with their colleagues, other healthcare workers and may be extended to include organization managers. Thus, frustration and anger might be created. Similarly, in the study of (Motamed-Jahromi et al., 2015). Nurses stated that accomplishing advocacy role is parallel to continuous conflict with other staff.

The current study showed that there was a significant negative correlation between attitude and advocacy behavior of nurses regarding care of critically ill elderly patients nurses have a negative attitude towards the care of the elderly even though they displayed a good knowledge of geriatric care. In the same line, (Ben Harush et al., 2016) professed that nurses who have negative attitudes towards older patients were tended to use patronizing speech with older adults and did not include them in discussions or decisions pertaining to their care plans. Instead, they approach younger family members or making decisions without any patient contribution. The current findings contra verse with other study done by (Subba et al., 2018) who reported that a significant correlation $(p=.003)$ between knowledge and attitude of nurses regarding ageing care.

It may explained by, the effective care of the elderly requires extraordinary training, provision of geriatric ward, continuing education on quality of care and adequate staffing to reduce stress and to improve nursing practice in the care of the elderly.

Current study's results are anticipated to be the foundation of improving a critical care nurse's 
knowledge, attitude and advocacy behavior toward caring of geriatric patients within critical care setting continuing relevant educational training of the nursing staff on geriatric nursing care that reflected on quality of nursing health services.

\section{Conclusion Recommendations}

Based on the findings of the current study we can conclude that there is no significant relationship between nurses' knowledge, attitudes toward ageism and geriatric patient advocacy behaviors. Also, the majority of the nurses have negative attitude toward ageism while more than half of them have moderate of geriatric patient advocacy behaviors.

Acknowledgements

A special thanks to the all ICU nurses in the different intensive care units at Aswan city hospitals

\section{Recommendations}

The following recommendations could be suggested:

- Design, appliance, and appraise suitable interventions and continuing education agendas by gerontological nursing for critical care nurses caring for older adults, especially in the acute care settings in order to enforce positive attitudes towards older adults and improve behaviors by increasing their knowledge about this fast growing population.

- Outlining gaps in clinical nursing practices in the acute care settings through regular assessment and observation of nurses' attitudes and practices and provides feedback and future training plan directions.

\section{References}

- Abdou, C., Fingerhut, A., Jackson, J., \& Wheaton, F., (2016): Healthcare stereotype threat in older adults in the health and retirement study. American journal of preventive medicine, 50(2), 191-198.

- Abudu-Birresborn, D., McCleary, L., Puts, M., Yakong, V., \& Cranley, L., (2019). Preparing nurses and nursing students to care for older adults in lower and middle-income countries: A scoping review. International Journal of Nursing Studies, 92, 121-134.

- Barlem, J., Lunardi, V., Barlem, E., Ramos, A., Figueira, A., \& Fornari, N., (2015): Nursing beliefs and actions in exercising patient advocacy in a hospital context. Revista da Escola de Enfermagem da USP, 49(5), 811-818.

- Baumbusch, J., Leblanc, M., Shaw, M., \& Kjorven, M., (2016): Factors influencing nurses' readiness to care for hospitalised older people. International Journal of Older People Nursing, 11(2), 149-159
- Beck, E., McIlfatrick, S., Hasson, F., \& Leavey, G., (2017): Nursing home manager's knowledge, attitudes and beliefs about advance care planning for people with dementia in long-term care settings: A crosssectional survey. Journal of Clinical Nursing, 26(17-18), 2633-2645.

- Ben-Harush, A., Shiovitz-Ezra, S., Doron, I., Alon, S., Leibovitz, A., Golander, H., Ayalon, L., (2017): Ageism among physicians, nurses, and social workers: Findings from a qualitative study. European Journal of Ageing, 14(1), 39-48.

- Ben-Harush, A., Shiovitz-Ezra, S., Doron, I., Alon, S., Leibovitz, A., Golander, H., \& Ayalon, L., (2016): Ageism among physicians, nurses, and social workers: Findings from a qualitative study. European Journal of Ageing,14(1), 39-48.

- Berger, R., (2017): Aging in America: ageism and general attitudes toward growing old and the elderly. Open Journal of Social Sciences, 5(08), 183.

- Bratt, C., Abrams, D., Swift, H., Vauclair, C., \& Marques, S., (2018): Perceived age discrimination across age in Europe: From an ageing society to a society for all ages. Developmental psychology, 54(1), 167.

- Buttigieg, S., Ilinca, S., de Sao Jose, J., \& Larsson, A., (2018): Researching ageism in healthcare and long term care. In Contemporary perspectives on ageism (pp. 493-515). Springer, Cham.

- Caceres, B., (2019): Care of LGBTQ older adults: What geriatric nurses must know. Geriatric Nursing, 40(3), 342-343.

- Caterino, J., Kline, D., Leininger, R., Southerland, L., Carpenter, C., Baugh, C., \& Stevenson, K., (2019): Nonspecific symptoms lack diagnostic accuracy for infection in older patients in the emergency department. Journal of the American Geriatrics Society, 67(3), 484-492.

- De Almeida Tavares, J., Silva, A., Sá-Couto, P., Boltz, M., \& Capezuti, E., (2015): Portuguese nurses' knowledge of and attitudes toward hospitalized older adults. Scandinavian journal of caring sciences, 29(1), 51-61.

- Deasey, D., Kable, A., \& Jeong, S., (2018): An exploration of emergencynurses' understanding of the ageing process and knowledge of theirolder patient: A comparison between regional and metropolitan nursesin Australia.International Emergency Nursing,37,44-51.

- Dobrowolska, B., Jędrzejkiewicz, B., PilewskaKozak, A., Zarzycka, D., Ślusarska, B., Deluga, A., \& Palese, A., (2019): Age discrimination inhealthcare institutions perceived by seniors and students.NursingEthics, 26(2), 443-459 
- Doherty, M., Mitchell, E., \& O'Neill, S., (2016): Attitudes of healthcare workers towards older people in a rural population: A survey using the Kogan Scale. Nursing Research and Practice.

- Gillis, A., Macdonald, B., \& Macisaac, A., (2008): Nurses' Knowledge, Attitudes, and Confidence Regarding Preventing and Treating Deconditioning in Older Adults. The Journal of Continuing Education in Nursing,39(12), 547-554. doi:10.3928/00220124-20081201-07

- Hanks, R., (2010): Development and testing of an instrument to measure protective nursing advocacy. Nursing Ethics, 17 ( 2), 255-67.

- Hsu, M., Ling, M., \& Lui, T., (2019): Relationship between gerontological nursing education and attitude toward older people. Nurse Education Today, 74, 85-90.

- Josse-Eklund, A., Jossebo, M., Sandin-Bojö, A., Wilde-Larsson, B., \& Petzäll, K., (2014). Swedish nurses' perceptions of influencers on patient advocacy: A phenomenographic study. Nursing Ethics, 21(6), 673-683.

- Kang, Y., Moyle, W., Cooke, M., \& O'dwyer, S., (2017): An educational programme to improve acute care nurses' knowledge, attitudes and family caregiver involvement in care of people with cognitive impairment. Scandinavian Journal of Caring Sciences, 31(3), 631-640.

- Kaur S., Kumar A., Kaur B., Rani \& B., Ghai S., (2014): Knowledge and Attitude Regarding Care of Elderly Among Nursing Students: An Indian Perspective. J Nurs Care 3: 161.

- Lan, X., Chen, Q., \& Yi, B., (2019): Attitude of nurses toward the Care of Older Adults in China.Journal of Transcultural Nursing, 30, 597602.

- Liang, J., Li, Z., Dong, H., \& Xu, C., (2019): Prognostic factors associated with mortality in mechanically ventilated patients in the intensive care unit: a single-center, retrospective cohort study of 905 patients. Medicine, $98(42)$.

- Mohammed, R., \& Omar, A., (2019): Knowledge about elderly care and its relation to ageism attitude among undergraduate nursing students. American Journal of Nursing, 7(1), 73-78.

- Motamed-Jahromi, M., Abbaszadeh, A., Borhani, F., \& Zaher, H., (2012): Iranian Nurses' Attitudes and Perception towards Patient Advocacy. ISRN Nursing, 2012, 2(2),53-58.

- Nelson, J., Cook, P., \& Ingram, J., (2014): Utility of the theory of planned behavior to predict nursing staff blood pressure monitoring behaviours. Journal of clinical nursing, 23(3-4), 461-470.

- Oral, B., Gunay, O., \& Cetinkaya, F., (2018): Attitudes of health professionals working in a university hospital towards ageism. Medicine Science, 8(1), 117-122.

- Özdemir, Ö., \& Bilgili, N., (2016): Attitudes of Turkish Nursing Students Related to Ageism. The Journal of Nursing Research: JNR, 24(3), 211-216.

- Rhew, D., Letvak, S., \& McCoy, T., (2017): The Effects of an Educational Intervention on Emergency Nursesâ€тM Attitude, Knowledge, and Care Behaviors toward Older Adults. Biomedical Journal of Scientific \& Technical Research, 1(7), 1957-1963.

- Rosen, T., Stern, M., Elman, A., \& Mulcare, M., (2018): Identifying and initiating intervention for elder abuse and neglect in the emergency department. Clinics in geriatric medicine, 34(3), 435-451.

- Schroyen, S., Missotten, P., Jerusalem, G., Gilles, C., \& Adam, S., (2016): Ageism and caring attitudes among nurses in oncology. International Psychogeriatrics, 28(5), 749-757.

- Schulte, P., Warner, D., Martin, D., Deljou, A., Mielke, M., Knopman, D., \& Hanson, A., (2019): Association between critical care admissions and cognitive trajectories in older adults. Critical care medicine, 47(8), 1116-1124.

- Smith, A., (2015): Attitude, subjective norm, and perceived behavioral control as indicators for nurse educators' intention to use critical thinking teaching strategies: A structural equation model analysis.

- Subba, H., Subba, R., \& Poudyal, S., (2018): Knowledge and Attitudes of Nurses toward Caring of Elderly People in Health Care Sittings. Hindu, 134, 93-7.

- Sweed, H., (2016): Population Ageing: Egypt Report. Middle East Journal of Age and Ageing, 83(4013), 1-8.

- Swift, H., Abrams, D., Lamont, R., \& Drury, L., (2017): The risks of ageism model: How ageism and negative attitudes toward age can be a barrier to active aging. Social Issues and Policy Review, 11(1), 195-231.

- Tomaschewski-Barlem, J., Lunardi, V., Barlem, E., Ramos, A., Silveira, R., \& de Oliveira Vargas, M., (2016): How have nurses practiced patient advocacy in the hospital context?-a foucaultian perspective. Texto \& Contexto Enfermagem, 25(1), $1-9$.

- Vefikuluçay Yilmaz, D., \& Terzioglu, F., (2011): Development And Psychometric Evaluation Of Ageism Attitude Scale Among The University Students. Turkish Journal of Geriatrics/Türk Geriatri Dergisi, 14(3).

- Windle, P., Mamaril, M., \& Fossum, S., (2008): Perianesthesia Nursing Advocacy: An Influential Voice for Patient Safety. Journal of PeriAnesthesia Nursing, 23(3), 163-171. 